\title{
Supporting shared decision-making about cardiopulmonary resuscitation using a video-based decision-support intervention in a hospital setting: a multisite before-after pilot study
}

\author{
John J. You MD MSc, Dev Jayaraman MD MPH, Marilyn Swinton MSc, Xuran Jiang MSc, \\ Daren K. Heyland MD MSc
}

\section{Abstract}

Background: Inpatients are often prescribed cardiopulmonary resuscitation (CPR) without a shared decision-making process. Since implementation of decision aids into practice is highly sensitive to the clinical milieu, we performed a pilot study to refine our study procedures and to evaluate the acceptability and potential effectiveness of a shared decision-making intervention when implemented in a Canadian hospital setting.

Methods: In this before-after pilot study, we recruited patients and family members on the medical wards of 2 Canadian teaching hospitals between September 2015 and March 2017. The intervention consisted of viewing a CPR decision video and completing a values-clarification worksheet; follow-up discussion with the physician was encouraged. The primary feasibility outcome was acceptability of the video, and the primary effectiveness outcome was change in the Decisional Conflict Scale score (lower scores being more desirable) after the intervention. Participants rated the extent of shared decision-making using the CollaboRATE instrument.

Results: Of the 71 participants (43 patients with a mean age of 79.0 [standard deviation (SD) 11.4] yr and 28 family members with a mean age of 61.0 [SD 10.0] yr), 65 (92\%) rated the CPR decision video as good to excellent. The intervention was associated with an improvement in knowledge about CPR (+2.7 points, 95\% confidence interval [Cl] 2.2 to 3.3 , effect size 1.5) and a reduction in the Decisional Conflict Scale score $(-18.1$ points, $95 \% \mathrm{Cl}-21.8$ to -14.3 , effect size 1.4). The 36 participants who had a discussion with a physician about CPR after watching the video rated the extent of shared decision-making as 6.3 (SD 1.7) (possible maximum score 9). There was a nonsignificant decrease in the proportion of patients with a medical order for CPR after the intervention (71\% before v. $63 \%$ after, $p=0.06)$.

Interpretation: The CPR decision video was acceptable to patients and family members. Our decision-support intervention may improve knowledge, reduce decisional conflict and reduce the prevalence of medical orders for CPR in the Canadian hospital setting.

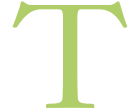
he development of cardiopulmonary resuscitation (CPR) in the late 20th century represents a major advance in the practice of medicine. ${ }^{1}$ However, media portrayals overestimate the efficacy of CPR, with an immediate success rate of $75 \%$ and a rate of survival to hospital discharge of $67 \% .^{2}$ In contrast, the rate of actual survival to hospital discharge after CPR for in-hospital cardiac arrest is $15 \%-20 \%{ }^{3,4}$ Moreover, survival rates are closer to $10 \%$ or lower among those with nonventricular tachycardia/ fibrillation arrest or serious underlying illness. ${ }^{5-9}$ Many inpatients do not have accurate knowledge of what interventions they would receive if CPR is performed (i.e., artificial breathing/intubation, chest compressions, defibrillation, drugs) or the likely outcomes of in-hospital CPR. In a Cana- dian multicentre survey of 440 older inpatients with lifelimiting illness, few patients (11\%) could describe more than 2 components of CPR, and only $3 \%$ thought that the success rate of CPR was less than $10 \% .{ }^{10}$

Decision aids can increase patients' knowledge of treatment options and outcomes, help them to clarify their values

Competing interests: None declared.

This article has been peer reviewed.

Correspondence to: John You, John.You@ thp.ca

CMAJ Open 2019. DOI:10.9778/cmajo.20190022 
and increase their participation in medical decisionmaking. ${ }^{11}$ For the current study, we chose to use a videobased decision-support intervention since low health literacy may be an important factor leading to poor understanding of the decision regarding CPR, and other investigators have found that video-based images can be a useful way to support decision-making. For instance, in a randomized controlled trial of community-dwelling older adults, patients and their substitute decision-makers were more likely to agree about the patient's preferences for CPR after viewing a video decision aid compared to a verbal description alone. ${ }^{12}$ Furthermore, a systematic review of video decision aids to assist with choices about use of life-sustaining treatments showed low- to medium-quality evidence that such tools can increase knowledge and change participants' preferences regarding CPR. ${ }^{13}$ However, little work has been done to evaluate the effect of video decision aids when integrated into clinical care, and this work has been restricted to the US context. ${ }^{14}$ Since implementation of decision aids into practice is highly sensitive to the clinical milieu, before proceeding with a larger evaluative trial, we performed a multicentre, beforeafter pilot study to refine our study procedures and to evaluate the acceptability and potential effectiveness of a shared decision-making intervention, including a CPR decision video and a values-clarification exercise, when implemented in a Canadian hospital setting.

\section{Methods}

\section{Design and setting}

Between Sept. 1, 2015, and Mar. 23, 2017, we conducted a before-after pilot study on the medical wards of 2 teaching hospitals: Hamilton General Hospital, Hamilton, Ontario and the Montreal General Hospital. Recruitment was from Sept. 1, 2015, to Aug. 15, 2016, and from Sept. 12, 2016, to Mar. 23, 2017, respectively.

\section{Participants}

Consistent with previous work, ${ }^{15,16}$ we identified a subset of inpatients at high risk for dying during the subsequent 6 months. Patients were eligible if 1 ) they were aged 80 years or more, 2) they were aged 55 years or more and had a chronic illness at an advanced stage (Appendix 1, available at www.cmajopen.ca/content/7/4/E630/suppl/DC1) or 3) a member of the health care team would not be surprised if the patient died in the next 6 months (when asked by a research assistant). Patients were excluded if they were unable to communicate owing to cognitive impairment or other medical reasons (e.g., too unwell, hearing impairment), or did not speak or read English. To mirror usual practice in the course of clinical care, if a patient met the inclusion criteria but could not participate because they also met at least 1 exclusion criterion (i.e., ultimately ineligible) or were eligible but refused to participate in the study, we approached family members, defined as people who knew the patient best, inclusive of partners, significant others and close friends (but excluding paid caregivers) who had visited the patient in the hospital at least once. Family members were excluded if they were unable to communicate owing to cognitive, visual, speech or hearing impairments, or if they did not speak or read English, as assessed by research staff.

\section{Cardiopulmonary resuscitation decision video}

The script for the CPR decision video is an adaptation from an earlier paper-based CPR decision aid that was developed based on a systematic review and input from experts during focus groups with physicians, nurses, a clinical ethicist and investigators from our research network (Canadian Researchers at End of Life Network [CARENET]). ${ }^{17,18}$ To develop the CPR decision video, we updated the content of the paper-based tool to include more contemporary data about the outcomes of inhospital CPR., ${ }^{3,5,7,19-22}$ A prototype version of the video was pilot tested in 3 focus groups: community-dwelling adults in Vancouver $(n=14)$ and Kingston $(n=30)$, and with CARENET investigators $(n=22)$. Responding to focus group feedback, we clarified the presentation of data, simplified the language, made explicit the alternative to CPR and compared outcomes of CPR to those without CPR. The final version is a 7 -minute video that was developed by a cinematographer in collaboration with the research team. It is in the public domain (www.youtube.com/ watch? $\mathrm{v}=\mathrm{aE} 6 \mathrm{bmNTUe} 5 \mathrm{E}$ www.youtube.com/watch? $\mathrm{v}=\mathrm{aE} 6 \mathrm{~b}$ $\mathrm{mNTUe} 5 \mathrm{E}$ ) and is designed for participants to view on a digital device screen. ${ }^{23}$

\section{Study procedures}

Part-time research assistants screened the medical records of patients who had been on the medical ward for 2-7 days, then approached eligible patients or their family members for consent to participate. Consistent with previous work, ${ }^{15,16}$ we used this time frame to allow enough time for initial symptoms to have abated so that study participants could engage with study personnel and tools, but to be early enough in the hospital stay that the intervention might influence decision-making during the index hospital stay. Baseline questionnaires included participants' demographic information, knowledge about CPR and the low-literacy version of the Decisional Conflict Scale (primary outcome) $)^{24,25}$ as it pertained to participants' current preference for CPR in the event of a cardiac arrest. Specifically, for the index decision, participants were asked to select 1 of 3 response options: have CPR if their heart stops, continue their current treatment plan but not receive CPR, or unsure. When responding to questions about preferences and decisional conflict, family members were asked to consider the patient's values and preferences related to CPR rather than their own opinions.

The CPR knowledge questionnaire consists of 9 questions developed by the research team to assess participants' knowledge about CPR. It has been used previously to evaluate the CPR decision video among patients with end-stage renal disease. Although the questionnaire was not formally pilot tested, it has a measure of content validity based on its development by content experts. ${ }^{26}$ Scores on the questionnaire can range from 0 to 9 , with 1 point given for each correct answer. The low-literacy version of the Decisional Conflict Scale is a 
10-item validated instrument consisting of 4 subscales that capture personal perceptions of feeling 1) uncertain about a treatment choice (Uncertainty subscale), 2) uninformed about choosing treatment options (Informed subscale), 3) unclear about personal values (Values Clarity subscale) and 4) supported in decision-making (Support subscale). The overall scale and each subscale are scored from 0 to 100 , with lower scores being more desirable. The low-literacy version has very good internal consistency (Cronbach $\alpha \geq 0.72$ ), fair construct validity (most correlation coefficients $\geq 0.40$, except the Support subscale) and an ability to discriminate between those who are precontemplative, those who are contemplative and those who have already decided..$^{25,27}$

After collection of baseline measures, a research assistant showed the participant the CPR decision video on a tablet or laptop computer. After viewing, the participant completed a paper-based worksheet consisting of a values-clarification exercise tailored to the specific decision about CPR that was developed based on available evidence, ${ }^{28}$ international consensus on best practices for shared decision-making ${ }^{29}$ and researchers' expertise in developing and implementing patient decision aids in clinical practice (Appendix 2, available at www.cmajopen.ca/content/7/4/E630/suppl/DC1). The research assistant then alerted the most responsible physician, senior medical resident or bedside nurse (in this order of preference) that the completed participant worksheet had been placed in the patient's chart and encouraged review of the completed worksheet and discussion of CPR preferences with the participant by a physician. Clinicians at participating sites did not receive any specific communication skills training as part of the study. A minimum of 48 hours after viewing the video, participants completed an acceptability questionnaire, the CPR knowledge questionnaire and the Decisional Conflict Scale (10-item low-literacy version). The acceptability questionnaire has been used previously to assess the CPR decision video in other settings ${ }^{26}$ and consists of validated questions asking about amount of information, length, clarity, balance in presentation, willingness to recommend to others and overall suitability for decision-making. ${ }^{30,31}$ Research assistants also asked participants whether there had been a discussion with a clinician about CPR after viewing the video. If so, participants were asked to complete the CollaboRATE instrument, a 3-item validated instrument to quantify the extent of shared decision-making (scored from 0 [no effort made] to 9 [every effort made]; higher scores are consistent with greater shared decision-making). ${ }^{32,33}$ Follow-up questionnaires were administered in person if patients had not yet been discharged or over the telephone if patients had been discharged. After hospital discharge, a research assistant conducted a chart review to document all medical orders written for the use or nonuse of CPR during the patient's hospital stay. All study questionnaires are included in Appendix 3 (available at www. cmajopen.ca/content/7/4/E630/suppl/DC1).

\section{Statistical analysis}

We described baseline characteristics of the study cohort and participant responses to the acceptability questionnaire using counts and proportions for categorical variables, and means and standard deviations (SDs) for continuous variables. We analyzed efficacy data using paired $t$ tests to compare scores on outcome measures of interest (i.e., knowledge about CPR and decisional conflict) before versus after the study intervention. We reported the change in scores as absolute differences with $95 \%$ confidence intervals and using the Cohen effect size (absolute difference divided by the pooled SD). ${ }^{34} \mathrm{We}$ used the $\mathrm{McNemar}$ test to compare medical orders for CPR on the day of enrolment and the last order during the patient's hospital stay. We used a complete case analysis approach for these analyses, i.e., we included only cases with nonmissing data for items before and after participants completed the study intervention. We compared the baseline characteristics of participants with evaluable data who had complete data and those with missing data for the primary effectiveness outcome (decisional conflict) to assess the potential risk of bias due to missing outcome data. We calculated that a sample size of 44 evaluable participants would provide $90 \%$ power with an $\alpha$ of 0.05 to detect an effect size of 0.5 in the change in the primary outcome from baseline to follow-up. An effect size of $0.2-0.3$ on the Decisional Conflict Scale discriminates between different decision-supporting interventions, and the developers of the instrument usually base sample size calculations on detecting an effect size of $0.3-0.4$. To be conservative, we based our sample size calculations on an ability to detect an even larger effect size of 0.5 . Recruitment was terminated after we had enrolled the required number of participants with evaluable data for the primary outcome. We used the SAS 9.4 statistical package (SAS Institute) to conduct the analyses. A $p$ value of 0.05 was considered statistically significant.

\section{Ethics approval}

This study received full approval from the Hamilton Integrated Research Ethics Board and the McGill University Health Centre Research Ethics Board.

\section{Result:}

We identified 341 eligible participants (patients and family members) and approached 107 for enrolment, of whom 76 consented to participate (Figure 1). Specifically, we identified 224 eligible patients and approached 46 for enrolment, of whom $43(93 \%)$ consented to participate. During this same period, we identified 117 eligible family members and approached 61 for enrolment, of whom 33 (54\%) consented to participate: $16(48 \%)$ were children, $6(18 \%)$ were spouses, $4(12 \%)$ were nieces and $2(6 \%)$ were sisters; information was missing for the remaining 5 (15\%). Exclusion of 5 family members who had missing data for $50 \%$ or more of items on baseline measures resulted in a final evaluable cohort of 71 participants (43 patients and 28 family members) (Table 1).

\section{Acceptability of study intervention}

Most of the participants (65 [92\%]) gave the CPR decision video a good to excellent overall rating and indicated that the tool provided the right amount of information in a balanced 


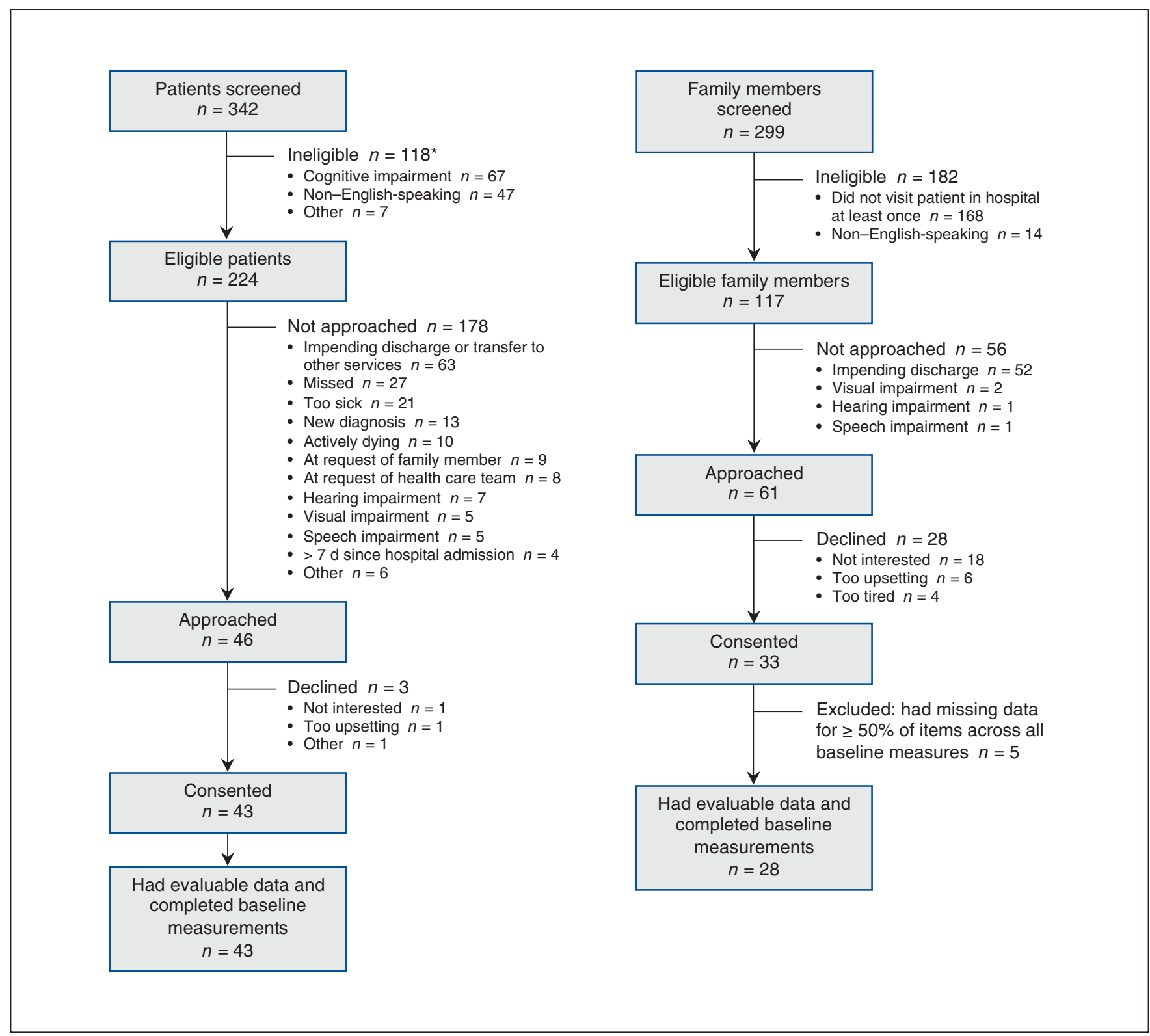

Figure 1: Flow diagram showing selection of study participants. *May have been excluded for more than 1 reason.

way, was clear and helpful, and was a tool that they would recommend to others (Table 2).

\section{Effectiveness of study intervention}

Fifty-two participants had nonmissing responses before and after viewing the CPR decision video. Their knowledge about CPR increased after viewing the video, from a mean score of 4.5 (SD 1.9) at baseline to 7.2 (SD 1.7) after viewing the tool (95\% confidence interval 2.2 to 3.3 , effect size 1.5 ). Participant responses to the CPR knowledge questionnaire are presented in Appendix 4 (available at www.cmajopen.ca/ content/7/4/E630/suppl/DC1).

Twenty-nine $(67 \%)$ of the 43 patients and 20 (71\%) of the 28 family members had nonmissing responses at baseline and follow-up for the Decisional Conflict Scale. Participants with complete data were more likely than those with missing data to be female, white and of Protestant or Catholic religious background (Appendix 5, available at www.cmajopen.ca/ content/7/4/E630/suppl/DC1). The mean baseline and follow-up scores on the Decisional Conflict Scale and its subscales for the 49 patients and family members with nonmissing data before and after the study intervention are reported in Table 3.

Of the 71 participants, $36(51 \%)$ had a discussion with a physician about CPR after watching the video. The mean score on the CollaboRATE instrument for these 36 participants was 6.3 (SD 1.7) out of a possible maximum score of 9 .

On the day of enrolment, 50 (71\%) of 70 participants had an explicit or implied (i.e., in the absence of a written order, the default is to perform CPR) medical order for CPR; 1 par- 
Table 1: Study population sociodemographic and health characteristics

\begin{tabular}{|c|c|c|}
\hline \multirow[b]{2}{*}{ Characteristic } & \multicolumn{2}{|c|}{ No. $(\%)$ of participants* } \\
\hline & $\begin{array}{c}\text { Patients } \\
n=43\end{array}$ & $\begin{array}{c}\text { Family } \\
\text { members } \\
n=28\end{array}$ \\
\hline Age, yr, mean \pm SD (range) & $\begin{array}{c}79.0 \pm 11.4 \\
(56-95)\end{array}$ & $\begin{array}{c}61.0 \pm 10.0 \\
(47-83)\end{array}$ \\
\hline Female sex & $23(53)$ & $25(89)$ \\
\hline \multicolumn{3}{|l|}{ Ethnicity } \\
\hline Asian/Pacific Islander & $0(0)$ & $2(7)$ \\
\hline African/black North American & $0(0)$ & $1(4)$ \\
\hline White & $42(98)$ & $23(82)$ \\
\hline First Nations/Inuit/Metis & $0(0)$ & $1(4)$ \\
\hline East Indian & $1(2)$ & $0(0)$ \\
\hline Other & $0(0)$ & $1(4)$ \\
\hline \multicolumn{3}{|l|}{ Formal religious group } \\
\hline Protestant & $17(40)$ & $8(29)$ \\
\hline Catholic & $11(26)$ & $11(39)$ \\
\hline Muslim & $0(0)$ & $1(4)$ \\
\hline Jewish & $1(2)$ & $0(0)$ \\
\hline None & $11(26)$ & $6(21)$ \\
\hline Other & $3(7)$ & $2(7)$ \\
\hline \multicolumn{3}{|l|}{ Highest level of education } \\
\hline Some high school & $19(44)$ & $2(7)$ \\
\hline Completed high school & $15(35)$ & $10(36)$ \\
\hline $\begin{array}{l}\text { Some university education or } \\
\text { completed other postsecondary } \\
\text { program }\end{array}$ & $7(16)$ & $8(29)$ \\
\hline University undergraduate degree & $2(5)$ & $5(18)$ \\
\hline University graduate degree & $0(0)$ & $3(11)$ \\
\hline \multicolumn{3}{|l|}{ Place of residence in prior month } \\
\hline Own home & $36(84)$ & - \\
\hline Retirement residence & $5(12)$ & - \\
\hline Rehabilitation facility & $1(2)$ & - \\
\hline Other & $1(2)$ & - \\
\hline \multicolumn{3}{|l|}{ Frailty†‡ } \\
\hline Well & $3(7)$ & - \\
\hline Managing well & $5(12)$ & - \\
\hline Vulnerable & $15(35)$ & - \\
\hline Mildly frail & $9(21)$ & - \\
\hline Moderately frail & $5(12)$ & - \\
\hline Severely frail & $1(2)$ & - \\
\hline Missing & $5(12)$ & - \\
\hline \multicolumn{3}{|l|}{ Self-rated quality of life $†$} \\
\hline Excellent & $3(7)$ & - \\
\hline Very good & $9(21)$ & - \\
\hline Good & $18(42)$ & - \\
\hline Fair & $9(21)$ & - \\
\hline Poor & $4(9)$ & - \\
\hline \multicolumn{3}{|c|}{ 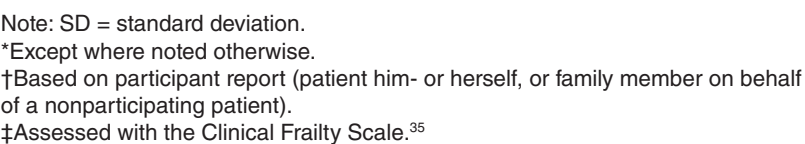 } \\
\hline
\end{tabular}

Table 2: Acceptability of cardiopulmonary resuscitation decision video

\begin{tabular}{cc}
\hline & No. (\%) of \\
participants \\
$n=71$
\end{tabular}

\section{Amount of information}

Much less than I needed 1 (1)

A little less than I needed $5(7)$

About the right amount $58(82)$

A little more than I needed $3(4)$

A lot more than I needed 3 (4)

Missing 1(1)

Balance of information about CPR

Clearly slanted toward having CPR 3 (4)

A little slanted toward having CPR 8 (11)

Completely balanced 46 (65)

A little slanted toward not having CPR 12 (17)

Clearly slanted toward not having CPR 1 (1)

Missing 1 (1)

\section{Clarity of information}

Many things were unclear 1 (1)

Some things were clear 1 (1)

Most things were clear 23 (32)

Everything was clear $\quad 46$ (65)

\section{Helpfulness in making decisions about} CPR

Not helpful 3 (4)

A little helpful 2 (3)

Somewhat helpful 35 (49)

Very helpful 31 (44)

Would recommend to others

I would definitely not recommend it 1 (1)

I would probably not recommend it 1 (1)

I would probably recommend it 26 (37)

I would definitely recommend it $43(61)$

\section{Overall rating}

Poo

Fair

Good

$35(49)$

Very good

$21(30)$

Excellent

Missing

Note: $\mathrm{CPR}=$ cardiopulmonary resuscitation . 
Table 3: Decisional Conflict Scale scores before and after the study intervention $(n=49)$

\begin{tabular}{|c|c|c|c|c|}
\hline \multirow[b]{2}{*}{ Item* } & \multicolumn{2}{|c|}{ Mean score \pm SD } & \multirow[b]{2}{*}{ Change $(95 \% \mathrm{Cl})$} & \multirow{2}{*}{$\begin{array}{l}\text { Effect } \\
\text { size }\end{array}$} \\
\hline & Before & After & & \\
\hline Total score & $25.7 \pm 17.4$ & $7.7 \pm 8.9$ & $-18.1(-21.8$ to -14.3$)$ & 1.3 \\
\hline Uncertainty subscore & $6.1 \pm 14.9$ & $3.6 \pm 11.4$ & $-2.6(-6.2$ to 1.1$)$ & 0.2 \\
\hline Informed subscore & $48.6 \pm 31.0$ & $15.6 \pm 21.1$ & $-33.0(-40.8$ to -25.2$)$ & 1.2 \\
\hline Values clarity subscore & $30.1 \pm 30.2$ & $5.1 \pm 12.5$ & $-25.0(-32.8$ to -17.2$)$ & 1.1 \\
\hline Support subscore & $12.9 \pm 21.9$ & $4.1 \pm 14.2$ & $-8.8(-14.4$ to -3.3$)$ & 0.5 \\
\hline
\end{tabular}

the clinical workflow. ElJawahri and colleagues ${ }^{14}$ implemented this videobased tool on the internal medicine services of 2 hospitals in Boston in a randomized controlled trial. Patients in the intervention arm watched the videobased tool, then had their preferences verbally communicated to physicians by a research assistant. They were more likely than the control group to have doc-
Table 4: Medical orders for use or nonuse of cardiopulmonary resuscitation at the time of enrolment and after the study intervention $\left(n=70^{*}\right)$

\begin{tabular}{|c|c|c|}
\hline \multirow[b]{2}{*}{ CPR order on day of enrolment } & \multicolumn{2}{|c|}{$\begin{array}{l}\text { Last documented CPR } \\
\text { order after study } \\
\text { intervention }\end{array}$} \\
\hline & CPR† & No CPR \\
\hline $\mathrm{CPR} \dagger$ & 42 & 8 \\
\hline No CPR & 2 & 18 \\
\hline \multicolumn{3}{|c|}{$\begin{array}{l}\text { Note: CPR = cardiopulmonary resuscitation. } \\
{ }^{*} \text { One participant was excluded from this analysis because the orders in the } \\
\text { medical record were unclear and could not be categorized. } \\
\text { tParticipants without an explicit order for the use or nonuse of CPR are } \\
\text { categorized as having an order for CPR in this table since that is what an } \\
\text { inpatient would receive by default in the absence of an order to the contrary. }\end{array}$} \\
\hline
\end{tabular}

ticipant had written orders that were unclear and was excluded from this analysis. After the study intervention, the prevalence of orders for CPR was 63\% (44/70) $(p=0.06)$ (Table 4).

\section{Interpretation}

In this multicentre, before-after pilot study, we found that the implementation of a CPR decision video in a medical ward setting was acceptable and, when combined with a paperbased values-clarification exercise, was associated with an increase in knowledge related to CPR, a reduction in decisional conflict, an appreciable degree of shared decisionmaking and a possible small decrease in the proportion of patients with medical orders for CPR.

Kapell Brown and colleagues ${ }^{26}$ recently tested the CPR decision video in a before-after study in a hemodialysis setting and found that the tool was associated with increased knowledge about CPR and an increase in the proportion of patients (14\% before v. $28 \%$ after) with orders not to perform CPR. In a series of US-based studies in different clinical settings, Volandes and colleagues ${ }^{36-41}$ found that a video-based tool can increase knowledge of CPR, reduce decisional conflict and change patient preferences for CPR; however, these studies did not embed the tool into umented discussions about their CPR preferences and to have medical orders to forgo CPR. Our findings are consistent with those of these previous studies in other settings and jurisdictions and suggest that a video-based decision aid for CPR may also be effective when implemented in Canadian teaching hospitals.

Our findings also suggest that, with the assistance of research personnel, our CPR decision video can be embedded into the clinical workflow on busy medical wards and may promote higher-quality decision-making about CPR. Furthermore, the video is in the public domain, which reduces barriers to its uptake. This is in contrast to other decision aids that are proprietary, which may pose barriers to broader uptake, especially in resource-constrained environments. One of the challenges we experienced was the incomplete follow-up by physicians with participants after they viewed the video. Although we did not collect data on the reasons why, potential barriers include competing priorities for physicians' time, patients' being discharged, physician discomfort with this topic, and insufficient communication from the research team to the clinical team that the video and worksheet had been completed. For teams who are planning to implement this tool in their local setting, we suggest considerable planning to develop strategies to reduce local barriers and capitalize on facilitators, and we recommend continuous evaluation of implementation processes and outcomes to monitor effectiveness. Our findings can also inform refinements to study procedures that could be used in future, larger evaluative trials of this decision-support intervention. For instance, greater investment of resources to engage physicians and hospital leadership may help to increase follow-up conversations by physicians with patients and families after they watch the video. In addition, our pilot study was hampered by low recruitment rates, most commonly because of patients' impending discharge from hospital. Modification of our study procedures to enrol patients earlier in the hospital stay (e.g., on the day of admission) may help to increase participation rates. Finally, to minimize missing outcome data, measurement burden could be reduced by limiting the number of questionnaires. Since our findings suggest that the tool is acceptable to participants and improves knowledge about CPR, investigators might consider omitting measurement of these more proximal outcomes in future studies. 


\section{Strengths and limitations}

Strengths of this work include the adherence to rigorous best practices in decision aid design and the availability of the tool in the public domain. This study also has limitations. First, because we did not use a concurrent control group, it is possible that the changes we observed were not due to the intervention itself but, rather, to other cointervention(s) (i.e., separate processes that occurred during a participant's enrolment in the study). However, it seems unlikely that participants' knowledge of CPR or decisional conflict would improve at 48 hours' follow-up for reasons other than exposure to the CPR decision video, given the low baseline levels of engagement in these conversations by hospital-based clinicians that has been observed in other studies. ${ }^{15,16}$ Second, the appreciable proportion of participants who had missing outcome data introduces a risk of bias, with systematic differences in sex, ethnicity and religious background among participants who were lost to follow-up. Third, we approached and enrolled only a subset of participants who were otherwise eligible for our study (43/224 [19.2\%] of eligible patients and 33/117 [28.2\%] of eligible family members). Furthermore, the overall number of eligible patients during the recruitment period was low relative to the number of patients on the medical wards during that same period. Therefore, the potential selectivity of our study sample introduces a risk of bias in our findings. If nonparticipating eligible people had views about the value of life prolongation or CPR that differed from those of our participants, this may have affected our study findings, and it is possible that our findings are an overestimate of the true effect. In addition, we conducted this work on the medical wards of Canadian teaching hospitals and enrolled only participants who could read and speak English, which may further limit the generalizability of our findings. Finally, when assessing the extent of shared decision-making using the CollaboRATE instrument, we relied on participant recall of interactions with their clinicians, which may not always have been accurate.

\section{Conclusion}

In this pilot study, our before-after evaluation of a publicly available CPR decision video suggests that the tool is acceptable to patients and families and, when combined with a values-clarification exercise, may improve knowledge about $\mathrm{CPR}$, reduce decisional conflict and increase the extent of shared decision-making. Further research, including qualitative approaches, is warranted to increase patients' and family members' participation in shared decision-making research, optimize implementation of the CPR decision video in a clinical environment and more rigorously evaluate its impact on clinical decision-making.

\section{References}

1. Zoll PM, Linenthal AJ, Gibson W, et al. Termination of ventricular fibrillation in man by externally applied electric countershock. $N$ Engl 7 Med 1956;254: 727-32.

2. Diem SJ, Lantos JD, Tulsky JA. Cardiopulmonary resuscitation on television. Miracles and misinformation. N Engl f Med 1996;334:1578-82.

3. Ehlenbach WJ, Barnato AE, Curtis JR, et al. Epidemiologic study of in-hospital cardiopulmonary resuscitation in the elderly. NEngl 7 Med 2009;361:22-31.

4. Girotra S, Nallamothu BK, Spertus JA, et al. Trends in survival after inhospital cardiac arrest. N Engl F Med 2012;367:1912-20.
5. Tian J, Kaufman DA, Zarich S, et al.; American Heart Association National Registry for Cardiopulmonary Resuscitation Investigators. Outcomes of critically ill patients who received cardiopulmonary resuscitation. Am 7 Respir Crit Care Med 2010;182:501-6.

6. Brindley PG, Markland DM, Mayers I, et al. Predictors of survival following in-hospital adult cardiopulmonary resuscitation. CMA7 2002;167:343-8.

7. Peberdy MA, Kaye W, Ornato JP, et al. Cardiopulmonary resuscitation of adults in the hospital: a report of 14720 cardiac arrests from the National Registry of Cardiopulmonary Resuscitation. Resuscitation 2003;58:297-308.

8. Peberdy MA, Ornato JP, Larkin GL, et al.; National Registry of Cardiopulmonary Resuscitation Investigators. Survival from in-hospital cardiac arrest during nights and weekends. $7 A M A$ 2008;299:785-92.

9. Ebell MH, Becker LA, Barry HC, et al. Survival after in-hospital cardiopulmonary resuscitation. A meta-analysis. 7 Gen Intern Med 1998;13:805-16.

10. Heyland DK, Frank C, Groll D, et al. Understanding cardiopulmonary resuscitation decision making: perspectives of seriously ill hospitalized patients and family members. Chest 2006;130:419-28.

11. Stacey D, Légaré F, Lewis K, et al. Decision aids for people facing health treatment or screening decisions. Cochrane Database Syst Rev 2017;(4):CD001431.

12. Volandes AE, Mitchell SL, Gillick MR, et al. Using video images to improve the accuracy of surrogate decision-making: a randomized controlled trial. $7 \mathrm{Am}$ Med Dir Assoc 2009;10:575-80.

13. Jain A, Corriveau S, Quinn K, et al. Video decision aids to assist with advance care planning: a systematic review and meta-analysis. BMF Open 2015;5:e007491.

14. El-Jawahri A, Mitchell SL, Paasche-Orlow MK, et al. A randomized controlled trial of a CPR and intubation video decision support tool for hospitalized patients. 7 Gen Intern Med 2015;30:1071-80.

15. You JJ, Dodek P, Lamontagne F, et al.; ACCEPT Study Team and the Canadian Researchers at the End of Life Network (CARENET). What really matters in end-of-life discussions? Perspectives of patients in hospital with serious illness and their families. CMA7 2014;186:E679-87.

16. Heyland DK, Barwich D, Pichora D, et al.; ACCEPT (Advance Care Planning Evaluation in Elderly Patients) Study Team; Canadian Researchers at the End of Life Network (CARENET). Failure to engage seriously ill hospitalized patients and their families in advance care planning: results of a multicenter prospective study. 7AMA Intern Med 2013;173:778-87.

17. Frank C, Pichora D, Suurdt J, et al. Development and use of a decision aid for communication with hospitalized patients about cardiopulmonary resuscitation preference. Patient Educ Couns 2010;79:130-3.

18. Frank C, Heyland DK, Chen B, et al. Determining resuscitation preferences of elderly inpatients: a review of the literature. CMAf 2003;169:795-9.

19. Larkin GL, Copes WS, Nathanson BH, et al. Pre-resuscitation factors associated with mortality in 49,130 cases of in-hospital cardiac arrest: a report from the National Registry for Cardiopulmonary Resuscitation. Resuscitation 2010; 81:302-11.

20. Nadkarni VM, Larkin GL, Peberdy MA, et al.; National Registry of Cardiopulmonary Resuscitation Investigators. First documented rhythm and clinical outcome from in-hospital cardiac arrest among children and adults. $7 A M A$ 2006;295:50-7.

21. Reisfield GM, Wallace SK, Munsell MF, et al. Survival in cancer patients undergoing in-hospital cardiopulmonary resuscitation: a meta-analysis. Resuscitation 2006;71:152-60.

22. Sandroni C, Nolan J, Cavallaro F, et al. In-hospital cardiac arrest: incidence, prognosis and possible measures to improve survival. Intensive Care Med 2007; 33:237-45.

23. Kryworuchko J, Fowler R, Heyland D, et al. A decision aid to prepare patients and their families for shared decision-making about cardio-pulmonary resuscitation (CPR). Vimeo; 2012. Available: https://vimeo.com/48147363 (accessed 2019 Oct. 12).

24. O'Connor AM. Validation of a decisional conflict scale. Med Decis Making 1995;15:25-30.

25. O'Connor AM. User manual - Decisional Conflict Scale. Ottawa: Ottawa Hospital Research Institute; 1993, updated 2010. Available: https://decisionaid. ohri.ca/docs/develop/User_Manuals/UM_Decisional_Conflict.pdf (accessed 2011 Feb. 18).

26. Kapell Brown C, Kryworuchko J, Martin W. Evaluation of the CPR video decision aid with patients with end stage renal disease. BMC Nephrol 2018;19:226.

27. Linder SK, Swank PR, Vernon SW, et al. Validity of a low literacy version of the Decisional Conflict Scale. Patient Educ Couns 2011;85:521-4.

28. Stacey D, Bennett CL, Barry MJ, et al. Decision aids for people facing health treatment or screening decisions. Cochrane Database Syst Rev 2011;(10):CD001431.

29. O'Connor A, Llewellyn-Thomas H, Stacey D, editors. IPDAS Collaboration background document. Ottawa: Ottawa Hospital Research Institute; 2005.

30. Barry MJ, Fowler FJ Jr, Mulley AG Jr, et al. Patient reactions to a program designed to facilitate patient participation in treatment decisions for benign prostatic hyperplasia. Med Care 1995;33:771-82.

31. Sepucha KR, Ozanne EM, Partridge AH, et al. Is there a role for decision aids in advanced breast cancer? Med Decis Making 2009;29:475-82.

32. Barr PJ, Thompson R, Walsh T, et al. The psychometric properties of CollaboRATE: a fast and frugal patient-reported measure of the shared decision-making process [published erratum in $\mathcal{7}$ Med Internet Res 2015;17:e32]. 7 Med Internet Res 2014;16:e2. 
33. Elwyn G, Barr PJ, Grande SW, et al. Developing CollaboRATE: a fast and frugal patient-reported measure of shared decision making in clinical encounters. Patient Educ Couns 2013;93:102-7.

34. Cohen J. A power primer. Psychol Bull 1992;112:155-9.

35. Rockwood K, Song X, MacKnight C, et al. A global clinical measure of fitness and frailty in elderly people. CMA7 2005;173:489-95

36. Volandes AE, Paasche-Orlow MK, Barry MJ, et al. Video decision support tool for advance care planning in dementia: randomised controlled trial. BM7 2009; 338:b2159.

37. El-Jawahri A, Podgurski LM, Eichler AF, et al. Use of video to facilitate end-oflife discussions with patients with cancer: a randomized controlled trial. 7 Clin Oncol 2010;28:305-10.

38. Volandes AE, Brandeis GH, Davis AD, et al. A randomized controlled trial of a goals-of-care video for elderly patients admitted to skilled nursing facilities. 7 Palliat Med 2012;15:805-11.

39. Volandes AE, Paasche-Orlow MK, Mitchell SL, et al. Randomized controlled trial of a video decision support tool for cardiopulmonary resuscitation decision making in advanced cancer. F Clin Oncol 2013;31:380-6.

40. Epstein AS, Volandes AE, Chen LY, et al. A randomized controlled trial of a cardiopulmonary resuscitation video in advance care planning for progressive pancreas and hepatobiliary cancer patients. 7 Palliat Med 2013;16:623-31.

41. El-Jawahri A, Paasche-Orlow MK, Matlock D, et al. Randomized, controlled trial of an advance care planning video decision support tool for patients with advanced heart failure. Circulation 2016;134:52-60.

Affiliations: Division of General and Hospitalist Medicine (You), Trillium Health Partners, Mississauga, Ont.; Department of Medicine (Jayaraman), McGill University, Montreal General Hospital, Montréal, Que.; Department of Health Research Methods, Evidence, and Impact
(Swinton), McMaster University, Hamilton, Ont.; Clinical Evaluation Research Unit (Jiang), Kingston General Hospital and Queen's University; Department of Critical Care Medicine (Heyland), Queen's University, Kingston, Ont.

Contributors: John You, Dev Jayaraman, Marilyn Swinton and Daren Heyland contributed to the conception and design of the study. John You, Dev Jayaraman and Marilyn Swinton acquired the data. John You, Xuran Jiang and Daren Heyland analyzed and interpreted the data. John You drafted the manuscript, and Dev Jayaraman, Marilyn Swinton, Xuran Jiang and Daren Heyland revised it critically for important intellectual content. All of the authors approved the final version to be published and agreed to be accountable for all aspects of the work.

Funding: This study was funded by Operating Grant CORE 2013-30A from the Canadian Frailty Network.

Acknowledgement: The authors thank research staff Carol Mantle and James Vatistas for their assistance in the collection and management of study data at participating sites.

Disclaimer: The funder had no role in the conception, design or execution of the study, data analysis or interpretation, drafting of the manuscript or the decision to publish.

Supplemental information: For reviewer comments and the original submission of this manuscript, please see www.cmajopen.ca/content/7/4/ E630/suppl/DC1. 